\title{
JUSTIÇA RESTAURATIVA COMO INSTRUMENTO DE TRANSFORMAÇÃO DE CONFLITOS: UMA ANÁLISE A PARTIR DE HOWARD ZEHR E JOHN PAUL LEDERACH.
}

\author{
RESTORATIVE JUSTICE AS A CONFLICT TRANSFORMATION INSTRUMENT: \\ AN ANALYSIS FROM HOWARD ZEHR AND JOHN PAUL LEDERACH THEORIES.
}

\author{
Henrique Ribeiro Cardoso ${ }^{1}$ \\ Fernando Gustavo Knoerr ${ }^{2}$ \\ Eliezer Siqueira de Sousa Júnior ${ }^{3}$
}

\begin{abstract}
RESUMO
Os métodos tradicionais de resolução de conflitos no campo penal vêm sofrendo diversas críticas, fazendo surgir recentemente diversos meios de lidar de forma diversa com o fato penal. A justiça restaurativa surge neste contexto como mecanismo poderoso a lidar com estes eventos, na medida em que propõe que as partes envolvidas construam, por elas mesmas, respostas melhores e mais eficientes ao evento criminal. Por outro lado, há de se ter cuidado para que estes novos outros meios não sejam levados a apenas impor uma solução para o conflito, desaguando nos mesmos problemas observados nos procedimentos clássicos. Desta forma, o presente artigo propõe a análise da justiça restaurativa, como formulado por Howard Zehr, na concepção da transformação de conflitos estabelecida por John Paul Lederach, transcendendo e complementando o velho modelo jurídico de imposição de decisões.
\end{abstract}

PALAVRAS-CHAVE: justiça restaurativa; transformação de conflitos; procedimento penal; justiça retributiva; mudança cultural.

\begin{abstract}
The traditional methods of conflict resolution in the criminal field have been criticized several times and have recently given rise to several means of dealing differently with the criminal case. Restorative justice appears in this context as a powerful mechanism to deal with these events, in that it proposes that the parties involved construct for themselves a better and more efficient response to the criminal event. On the other hand, care must be taken to ensure that

1 Promotor de Justiça em Sergipe desde agosto de 1997, titular da Primeira Curadoria da Fazenda Pública de Aracaju desde 2002. Também foi Advogado e Defensor Público na Bahia, tendo sido ainda nomeado, mediante aprovação em concurso público, para o cargo de Procurador da Fazenda do Estado da Bahia. No campo acadêmico, é Doutor em Direito, Estado e Cidadania (UGF/Rio), com Pós-doutorado em Democracia e Direitos Humanos (IGC - Universidade de Coimbra) e Pósdoutorado em Direitos Humanos e Desenvolvimento (PPGCJ/UFPB); Mestre em Direito, Estado e Cidadania (UGF/Rio); Especialista em Direito Constitucional Processual (FAPESE/UFS); Graduado em Direito pela Universidade Estadual de Santa Cruz (UESC/Bahia); Professor do Programa de Pósgraduação da Universidade Federal de Sergipe (Mestrado/PRODIR/UFS); Professor de Programa de Pós-graduação da Universidade Tiradentes (Mestrado/PPGD/UNIT); Professor da Escola Superior do Ministério Público de Sergipe (ESMP/SE).

2 Doutor em Direito do Estado pela Universidade Federal do Paraná (2002). Mestre em Direito do Estado pela Universidade Federal do Paraná (1998). Bacharel em Direito pela Universidade Federal do Paraná (1993). Ex-Procurador Federal. Professor de Direito Administrativo da Escola da Magistratura do Paraná e da Fundação Escola do Ministério Público do Paraná / FEMPAR. É Professor Permanente do Programa de Mestrado em Direito Empresarial e Cidadania do UNICURITIBA. Realizou estágio Pós- Doutoral na Universidade de Coimbra, Portugal (2015-2016).

${ }^{3}$ Mestrando em Constitucionalização do Direito na Universidade Federal de Sergipe (UFS); Juiz Substituto do Tribunal de Justiça de Sergipe (TJSE).
\end{abstract}


these new means do not lead only to impose a solution to the conflict, leading to the same problems observed in the classical procedures. In this way, the present article proposes the analysis of restorative justice, as formulated by Howard Zehr, in the conception of the transformation of conflicts established by John Paul Lederach, surpassing and complementing the old legal model of imposition of decisions.

KEYWORDS: restorative justice; conflict transformation; criminal proceedings; retributive justice; cultural change. 


\section{INTRODUÇÃO}

Em um mundo cada vez mais secularizado $^{1}$, onde fenômenos de mudanças socioeconômicas e culturais, como a globalização, são cada vez mais frequentes e determinantes para a mudança de paradigmas humanos, as tradições das comunidades locais vêm perdendo espaço para ditames universais no que tange à forma de enxergar e lidar com os conflitos ocorridos ao seu redor.

Some-se a isto o aumento da pluralidade e complexidade das relações sociais que, graças ao avanço científico, à evolução tecnológica, crises econômicas, dentre tantos outros fatores, vêm produzindo uma série de consequências observadas na vida comezinha dos cidadãos e na sociedade a que pertencem. Uniões homoafetivas, aborto de feto anencéfalo, delitos cibernéticos, proteção ao meio ambiente são, por exemplo, questões surgidas dentro deste contexto de mudanças sociais que, comumente, suscitam conflitos interpessoais e ultrapassam as fronteiras tradicionalmente demarcadas e conhecidas.

A seara penal, nesta nova realidade, não passa incólume: novas questões provocam novos conflitos, que revelarão, em algum grau, genérico ou específico, interesse da norma penal em tutelar eventuais lesões a bens jurídicos, novos ou perenes, tutelados pelo direito. $\mathrm{O}$ que se extrai, também, é que o modelo tradicional de lidar com estes conflitos, especificamente os procedimentos previstos pelo direito processual penal, vai se revelando insuficiente para estas questões e, principalmente, com seus efeitos, tornando ineficiente a sua aplicação, carecendo, ainda, de mínima aceitabilidade social.

Há muito se observa movimentos das mais diversas ordens para a criação de métodos, técnicas e procedimentos aptos a não só dar uma resposta tradicional ao descumprimento da norma penal, seja material ou processual, como também apresentar soluções mais efetivas para lidar com os conflitos nesta área do sistema jurídico.

Como resposta a estas indagações, a justiça restaurativa surge como elemento procedimental apto a oportunizar às partes envolvidas num conflito relevante ao direito penal que produzam, por si mesmas, uma solução que seja produto de um caminho trilhado pela

1

“O fenômeno histórico-social da secularização está intimamente relacionado com o avanço da modernidade. O direito, a arte, a cultura, a filosofia, a educação, a medicina e outros campos da vida social moderna se baseiam em valores seculares, ou seja, não religiosos". (RANQUETAT JÚNIOR, César A. Laicidade, laicismo e secularização: definindo e esclarecendo conceitos. Santa Maria. Revista Sociais \& Humanas CCSH/UFSM. V. 21. n. 1. 2008. p. 67). 
vítima, o ofensor, seus apoiadores, a comunidade e a sociedade ${ }^{2}$ envolvida no conflito.

E como lidar com estes conflitos? No presente artigo, busca-se, inicialmente, uma análise oferecida por John Paul Lederach sobre o conflito e sua transformação, em oposição ao vernáculo "resolução", e a partir dela, analisar a justiça restaurativa, e sua concepção fornecida por Howard Zehr, como forma salutar para lidar, e quiçá, efetivamente transformar os conflitos ocorridos em nossa sociedade.

\section{A transformação de conflitos em John Paul Lederach.}

Em seu livro "Transformação de conflitos”, John Paul Lederach relata, já no seu início, a sua experiência nos anos 80 na América $\mathrm{Central}^{3}$, onde se deparou com a desconfiança com que seus colegas locais, de origem latina, recebiam as expressões "resolução" ou "gerenciamento" de conflitos.

Para eles, tais locuções deixavam em aberto espaço para interpretações comunicativas estratégicas $^{4}$, que indicavam uma cooptação, uma forma pragmática de se ver livre do conflito, independentemente da solução alcançada, não deixando claro, ainda, se estes procedimentos de resolução de conflitos permitiam que as partes envolvidas poderiam, cada qual, defender e argumentar a sua posição ${ }^{5}$. Esta experiência, aliada à visão de mundo e religiosa de Lederach, fundada na ideia de que a paz está fundada na noção de justiça, levou-o a mudar sua forma de observar o conflito e na maneira de lidar com ele.

Propõe-se que, em vez de "resolver" de qualquer forma o conflito, sem ouvir ou proporcionar aos envolvidos a oportunidade de participarem do processo de construção das soluções a serem aplicadas, os conflitos devem ser encarados como eventos normais nos relacionamentos humanos, revelando-se, invariavelmente, em grande propulsor de mudanças, e que, ao invés de serem vistos tão-somente como problemas específicos e pontuais, devem ser vistos e tratados como vetores voltados a uma mudança construtiva de paradigmas pessoais e sociais ${ }^{6}$.

A transformação ultrapassa à elaboração e aplicação de um conjunto de técnicas e

2 Utilizou-se as expressões "comunidade" e "sociedade" para se referir, respectivamente, a um grupo menor ou maior de indivíduos pertencentes a um mesmo contexto social.

3 Muito embora o livro não fale explicitamente, Lederach teve, nos anos 80, participação ativa em conflitos ocorridos na Nicarágua e Colômbia.

$4 \quad$ O sentido de "estratégico", aqui, é em contraposição ao "comunicativo" articulado por Jürgen Habermas. Ou seja, estratégico se liga à ideia de egoístico, solipsista.

5 LEDERACH, John Paul. Transformação de conflitos. Tradução de Tônia Van Acker. São Paulo. Palas Athena. 2012. p. 15.

6 Ibidem. p. 16-17. 
métodos específicos para lidar com estes conflitos: fornece um modo de olhar e enxergar estes problemas e, mais ainda, buscar soluções efetivas para estas tensões. Para tanto, utilizando uma metáfora sobre lentes ${ }^{7}$, apresenta três formas de enxergar os problemas: a primeira para ver a situação imediata; a segunda voltada para visualizar padrões mais profundos de relacionamento; a terceira preocupada em estabelecer estruturas capazes de notar as ligações entre os problemas imediatos e os padrões de relacionamentos ${ }^{8}$.

Em um grupamento social de maior ou menor proporção, é importante perceber que a transformação de conflitos deve viabilizar o resgate de um equilíbrio institucional, buscando harmonizar os plúrimos contextos sociais e trazer para a justiça o sentido de atividade que, mais do que tornar o malfeito em bem feito, vindique as vítimas, reconcilie as partes e restabeleça a paz ${ }^{9}$.

Mais do que estabelecer que a justiça, enquanto ordem social de anseio eterno da humanidade, seja "a felicidade que o homem não pode encontrar como indivíduo isolado e que, portanto, procura em sociedade" 10 , impõe-se racionalizar (e entender) que há diferentes noções de justiça, frequentemente contraditórias, revelada, não raras as vezes, como resultado frio e formal da resolução do conflito de interesses ${ }^{11}$.

Ao direito depositou-se a missão de oferecer respostas a conflitos originados por interesses opostos, garantindo a paz social e a estabilidade das soluções determinadas por seu sistema. Entretanto, em nome da propalada segurança jurídica, produzem-se decisões com o objetivo de restabelecer a paz, a normalidade e a tranquilidade social em detrimento de direitos caros dos indivíduos, que em determinados contextos pertencem a grupos que não possuem meios nem maneiras de promover seus direitos.

Transformar conflitos consiste em enxergar estes fluxos como oportunidades para criar processos construtivos de mudanças que se dirijam a reduzir a violência, aumentem o sentido

7 Tal metáfora também é utilizada por Howard Zehr, cujo livro mais famoso é intitulado "Trocando as lentes", que será abordado no decorrer deste artigo.

8 LEDERACH, John Paul. Transformação de conflitos. Tradução de Tônia Van Acker. São Paulo. Palas Athena. 2012. p. 23. O autor cita uma alegoria sobre a louça suja do jantar em sua família para demonstrar seu ponto de vista. A pergunta "Quem vai lavar a louça hoje à noite?", muitas vezes não se dirige, tão-somente, à solução rápida, sobre quem vai, efetivamente, lavar a louça. Trata de diversos conflitos existentes entre quem cozinha, quem lavou na noite anterior, quem trabalha até tarde, quem ganha mais dinheiro, quem é mais velho, quem é mais novo, cada um entendendo que não deve, ou que não quer mesmo lavar a louça do jantar.

9 SCURO NETO, Pedro; PEREIRA, Renato Tardelli. A justiça como fator de transformação de conflitos: princípios e implementação. São Paulo. Simpósio Internacional da iniciativa privada para a prevenção da criminalidade. NEST/Câmara de Comércio e Indústria Brasil/Alemanha. 2000. p. 3.

10 KELSEN, Hans. Teoria geral do direito e do estado. Tradução de Luís Carlos Borges. $3^{\mathrm{a}}$ ed. São Paulo. Martins Fontes. 1998. p. 09.

11 SCURO NETO, Pedro; PEREIRA, Renato Tardelli. Ibidem. 
e sentimento de justiça nas interações e estruturas sociais, como método assertivo e eficiente de lidar com os problemas cotidianos advindos dos mais variados relacionamentos humanos. Ou seja, além de se destinar a estancar determinados episódios de violência, a transformação de conflitos se destina à promoção de mudanças individuais, relacionais, estruturais e culturais que residem nos denominados "epicentros do conflito"12.

Ressalte-se que esta acepção, a de transformação, não afasta os mecanismos tradicionais do direito de defrontar os conflitos, mas aponta que a mera resolução não consegue descobrir e lidar adequadamente com questões cruciais dos episódios dos embates entre as partes, buscando assim, solucioná-los da forma mais efetiva e completa possível. É uma abordagem que não surge só para substituir os métodos clássicos (ainda que em alguns casos possa acontecer ${ }^{13}$ ), mas para complementar e subsidiar a procura dos problemas aparentes e submersos e a proposta de soluções mais condizentes com o caso concreto, afastando o consenso imposto ${ }^{14}$.

Transformar conflitos significa focar (n)o relacionamento em questão, visualizar o episódio atual como oportunidade de responder aos sintomas latentes e envolver os sistemas que o relacionamento esteja inserido, dentro de uma dinâmica relacional com vazante (desescalada do conflito a fim de buscar mudanças construtivas) e enchente (escalada do conflito para buscar mudanças também construtivas) $)^{15}$.

Nesta ótica, revela-se como uma soma de resolução de conflitos (onde se busca por termo ao que, naquela relação específica, não funciona ou não está bom) e construção de estruturas voltadas à criação de algo melhor no relacionamento em questão. No campo

12 FACCHINI, Julia. O local nos estudos sobre peacebuilding: uma análise das obras de John Paul Lederach e Roger Mac Ginty. 26 f. Trabalho de Conclusão de Curso (Graduação em Relações Internacionais) Universidade Federal de Uberlândia. Uberlândia. 2017. p. 8-9. Lederach, ao diferenciar episódio e epicentro, aponta que um episódio é a expressão visível de um conflito que surge ou está em processo de surgimento dentro do relacionamento e do sistema, geralmente dentro de uma estrutura temporal definida, ao passo que o epicentro é a teia de padrões relacionais, ligada comumente ao histórico de episódios ocorridos, e fonte de novos episódios. E arremata: "Se o episódio libera energia conflitual para o relacionamento, o epicentro é o local onde a energia é produzida". (LEDERACH, John Paul. Transformação de conflitos. Tradução de Tônia Van Acker. São Paulo. Palas Athena. 2012. p. 46).

13 Já se tem defendido que a justiça restaurativa, entre nós, pode substituir os métodos tradicionais, por exemplo, nos crimes de menor potencial ofensivo. Sobre o assunto, ver o programa "Profissão: Repórter", exibido no dia 31 de outubro de 2018. Disponível em < https://globoplay.globo.com/v/7129592>.

14 O consenso universal, aparentemente coletivo, revela-se como consenso imposto, na medida em que invariavelmente é produzido por e no interesse de poucos países, nem sempre por razões humanitárias (SUXBERGER, Antônio Henrique Graciano. Críticas ao consenso universal impositivo. p. 83. In: $70^{\circ}$ aniversario de la declaración universal de derechos humanos: La protección internacional de los derechos humanos en cuestión. Valencia. Tirant lo Blanch. 2018).

15 LEDERACH, John Paul. Transformação de conflitos. Tradução de Tônia Van Acker. São Paulo. Palas Athena. 2012. p. 48. 
procedimental, tal afirmação se confirma, na medida em que o que funciona nos denominados modelos tradicionais devem ser mantidos e melhorados, abrindo mão dos modelos preestabelecidos e impostos aos métodos locais de reconstrução social que atrapalhem a consolidação da paz real ${ }^{16}$, produto de um processo maduro e efetivo de transformação dos conflitos em oportunidades de crescimento para todos.

\section{A justiça restaurativa.}

Howard Zehr, adaptando definição dada por Tony Marshall, apresenta a justiça restaurativa, para fins operacionais, como:

"um processo para envolver, tanto quanto possível, todos aqueles que têm interesse em determinada ofensa, num processo que coletivamente identifica e trata os danos, necessidades e obrigações decorrentes da ofensa, a fim de promover o restabelecimento das pessoas e endireitar as coisas, na medida do possível"17.

Noutro giro, a justiça restaurativa se apresenta como uma nova linguagem voltada a lidar com conflitos, como movimento social, como técnica de solução de conflitos e como política pública dos poderes constituídos, propondo enfoques sobre novos paradigmas e com soluções que levem em conta a vontade das partes na construção dos resultados destinados à construção do futuro, afastando-se da forma tradicional de resposta ao delito, que se baseia no mero olhar voltado ao passado ${ }^{18}$.

Como nova linguagem, a justiça restaurativa propõe uma nova leitura sobre o conflito, valorizando a democracia participativa ${ }^{19}$ como vetor determinante para atingir o respeito aos

16 Utiliza-se a expressão "paz real" em oposição à "paz imposta" por procedimentos observados por Lederach na aplicação dos processos de "peacebuilding" pelas Nações Unidas, onde os modelos eram préelaborados e aplicados sem levar em conta as realidades locais. Como visto, tais construções de paz, além de artificiais, não resolviam a contento os problemas por não considerarem as necessidades dos envolvidos. (FACCHINI, Julia. O local nos estudos sobre peacebuilding: uma análise das obras de John Paul Lederach e Roger Mac Ginty. 26 f. Trabalho de Conclusão de Curso (Graduação em Relações Internacionais) - Universidade Federal de Uberlândia. Uberlândia. p. 1).

17 ZEHR, Howard. Justiça restaurativa. Tradução Tônia Van Acker. São Paulo. Palas Athena. 2012. p. 49. Em nota de fim de texto (p. 84), o autor traz a definição original do autor apontado no texto: "Justiça Restaurativa é um processo através do qual todas as partes interessadas numa ofensa específica se reúnem para decidir coletivamente como lidar com as consequências da ofensa e suas implicações para o futuro".

18 SILVA, Haroldo Luiz Rigo da. Justiça restaurativa - instrumento de efetivação do princípio constitucional da felicidade: um estudo sobre a prática em Sergipe. Dissertação (mestrado em Direito). São Cristóvão. UFS. 2017. p. 15.

19 "A democracia deliberativa para Habermas se constituí a partir de conjuntos de procedimentos e de 
direitos relacionados ao conflitos, em seus mais variados aspectos, nos mais variados espaços sociais em que esta forma de abordagem dos conflitos se faça presente.

Como movimento social, a justiça restaurativa se lança sobre os espaços públicos onde as violações de direitos humanos acontecem, auxiliando as instituições públicas e privadas na apresentação de respostas adequadas aos conflitos, promovendo a integração dos diversos movimentos sociais de maneira abrangente.

Surge, assim, como poderosa ferramenta para lidar com conflitos, apresentando soluções de modo estruturado, com participação de todos os envolvidos e interessados no fato delituoso (vítima, ofensor, famílias, comunidade e sociedade ${ }^{20}$ ), coordenados por facilitadores capacitados em técnicas voltadas à autocomposição e resolução consensual de conflitos, tendo por objetivo a satisfação das necessidades dos participantes, a responsabilização dos que contribuíram, direta ou indiretamente, para a prática delitiva e suas consequências danosas e o resgate da autoridade da comunidade e da sociedade para solucionar conflitos, com a devida reparação dos danos e recomposição do sentido e do sentimento social ${ }^{21}$.

É curial ressaltar que a justiça restaurativa suplanta a ideia tradicional de (re)solução de conflitos, estabelecendo um novo e verdadeiro estilo de vida social, destinado à promoção de uma cultura de paz, (re)estabelecendo todas as dimensões de convivência - relacional, institucional e social - efetivando a construção de laços com outro, estabelecendo uma corresponsabilidade entre os envolvidos pela transformação dos $\operatorname{conflitos}^{22}$, para construir uma comunidade harmoniosa e uma sociedade mais justa e humana.

atos, que tenham por base o discurso e a deliberação racional. O que determina a legitimidade é o processo de tomada de decisões políticas, frutos de discussão pública ampla e igualitária em que os participantes, interessados direta e indiretamente, os concernidos, possam debater o tanto quanto venham julgar necessário a partir dos argumentos válidos e reconhecidos, a fim de que as decisões obtidas sejam assumidas por todos e todas como suficientemente corretas e frutos de consensos em vista de interesses comuns à existência coletiva. A democracia deliberativa se fundamenta racionalmente e isso significa a utilização da deliberação ou discurso por parte dos cidadãos como participação política. Portanto, já não é somente o voto que garante a legitimidade, mas principalmente a participação discursiva dos interessados que são direta e indiretamente afetados pelas decisões que venham a ser tomadas. E isso necessariamente amplia a ideia de soberania popular". (GOMES, Ronaldo Martins. A democracia deliberativa de Jürgen Habermas. São Carlos. Anais do Seminário dos Estudantes da PósGraduação em Filosofia da UFSCar. VIII Edição. 2012. p. 492).

20 Neste contexto, comunidade e sociedade se distinguem pela dimensão menor (comunidade) ou maior (sociedade) do grupamento humano envolvido.

21 SALMASO, Marcelo Nalesso. Uma mudança de paradigma e o ideal voltado à construção de uma cultura de paz. In: BRASIL. Conselho Nacional de Justiça. Justiça restaurativa: horizontes a partir da Resolução CNJ 225. Coordenação: Fabrício Bittencourt da Cruz. Brasília. CNJ. 2016. p. 38.

22 Expressão utilizada por John Paul Lederach que, em sua experiência nos anos 80 pela América Central, percebeu que a expressão "resolução de conflito", em alguns contextos, trazia uma noção de cooptação, uma tentativa de se livrar do conflito, não deixando claro se os envolvidos teriam espaços para defender as suas posições (LEDERACH, John Paul. Transformação de conflitos. Tradução de Tônia Van Acker. São Paulo. Palas Athena. 2012). 
As vantagens da justiça restaurativa são inúmeras: promove uma releitura dirigida a uma solução a ser dada ao conflito; legitima a decisão final, pois produzida pela efetiva participação dos envolvidos; desafoga os escaninhos do Poder Judiciário, pois as soluções, ainda que produzidas com a participação de facilitadores formados no âmbito do Poder Judiciário, serão dadas previamente pelos participantes, cabendo ao Juiz analisar aspectos formais e legais das soluções apresentadas; participação de equipes multidisciplinares e extrajudiciais no sistema da justiça restaurativa, o que potencializa a produção de ambientes seguros e aplicação de técnicas mais eficientes para a produção de resultados desejados, dentre outros ${ }^{23}$.

No tocante à técnica de solução de conflitos, a justiça restaurativa se revela não como um método, mas como várias técnicas a serem utilizadas em cada caso concreto, como são os casos do Círculo de Construção de Paz, Comunicação Não Violenta, Planejamento e Gestão Dragon Dreaming, Mediação Vítima-Ofensor, dentre outros ${ }^{24}$.

Ainda, como política pública, a justiça restaurativa está devidamente inserida no planejamento estratégico do Poder Judiciário, aparecendo como meta do Conselho Nacional de Justiça (CNJ), que através da Resolução no 225/2016 passou a disciplinar o funcionamento da justiça restaurativa dentro da estrutura do Poder Judiciário, envolvendo atores de diversas áreas, como saúde, educação, segurança pública e membros da sociedade civil ${ }^{25}$.

Voltando às concepções de Howard Zehr, é curial demonstrar que, para chegar a uma definição do que seja a justiça restaurativa, o autor perpassa pelas ideias do que não seja a justiça restaurativa. Assim, em sua concepção, a justiça restaurativa não tem como objeto principal o perdão ou a reconciliação dos envolvidos, pois se tivesse este norte poderia levar às partes à errônea ideia de que seriam forçados a perdoar ou reconciliar a qualquer custo.

Da mesma maneira, a justiça restaurativa não é espécie de mediação, na medida em que a mediação, geralmente, ocorre em um único encontro das partes e pressupõe um mesmo nível ético das partes, com responsabilidades a serem partilhadas. A justiça restaurativa se volta a identificar as necessidades dos envolvidos, o que pode demandar bem mais do que um

23 SILVA, Haroldo Luiz Rigo da. Justiça restaurativa - instrumento de efetivação do princípio constitucional da felicidade: um estudo sobre a prática em Sergipe. Dissertação (mestrado em Direito). São Cristóvão. UFS. 2017. p. 15.

24 ZEHR trabalha de maneira aprofundada com cada um destes expedientes, abordando de forma prática a essência e o funcionamento de cada um destes mecanismos (ZEHR, Howard. Justiça restaurativa. Tradução Tônia Van Acker. São Paulo. Palas Athena. 2012. p. 53-70).

25 SILVA, Haroldo Luiz Rigo da. Justiça restaurativa - instrumento de efetivação do princípio constitucional da felicidade: um estudo sobre a prática em Sergipe. Dissertação (mestrado em Direito). São Cristóvão. UFS. 2017. p. 15. 
encontro, em diversas frentes, até mesmo para se ter certeza que o contato entre ofensor e vítima vá ser frutífero, bem como se baseia, na maioria dos casos, na admissão, por parte do ofensor, de algum nível de responsabilidade na ofensa.

A justiça restaurativa também não visa reduzir a reincidência ou as ofensas reiteradas, muito embora isto possa ser atingido. A diminuição da criminalidade é um subproduto, que é decorrência da ideia de se buscar, primordialmente, qual a coisa certa a se fazer em cada caso. A vítima deve ter suas necessidades atingidas, o ofensor deve admitir algum grau de culpa, os envolvidos devem buscar ativamente entender seu papel neste processo, independentemente do fato de que novos conflitos poderão (res)surgir.

Também não se revela em um substituto para o processo penal, pois não é a resposta para todas as questões. Em muitas questões, pode sim substituir o procedimento tradicional. Em outros casos, atua em paralelo e até posteriormente, como no caso de aplicação na execução penal.

Por fim, ela não se mostra como alternativa ao aprisionamento pois, como vimos, pode ser aplicada dentro do próprio contexto da execução das penas restritivas de liberdade, nem se contrapõe, necessariamente, à denominada justiça retributiva ${ }^{26}$.

Sobre a justiça retributiva, sua incapacidade de reabilitar ou ressocializar não se deve, primordialmente, às deficiências de seu sistema. É de se destacar que o modelo retributivo é unidimensional, calcado no paradigma retributivo entre punir e reabilitar, o que revela a contradição entre o atender às necessidades coletivas (com a segregação do perigo e, principalmente, dos elementos que promovam estes perigos através de rigorosa punição) e satisfazer as carências individuais (através de métodos e programas específicos voltados à ressocialização do indivíduo a margem da lei).

Assim, a justiça restaurativa enxerga o crime não apenas como uma violação à lei e afronta ao Estado, mas como um rompimento de relacionamentos e pessoas, gerando destas violações, ao invés de culpa, obrigações e responsabilidades a serem visualizadas por todos os envolvidos no conflito que, dentro de suas possibilidades, devem agir para corrigir os efeitos da prática delitiva, levando em conta as necessidades da vítima e a responsabilidade do ofensor de reparar o dano cometido, exigindo e proporcionando aos envolvidos engajamento e ativa participação para a construção da melhor solução a ser dada.

26 ZEHR, Howard. Justiça restaurativa. Tradução Tônia Van Acker. São Paulo. Palas Athena. 2012. p. 1823. Sobre este último ponto, o autor afirma, na página 23 da citada obra, já apresentou a justiça restaurativa em oposição à justiça retributiva, no que apresentou mudança de entendimento, como delinearemos a seguir. 
Aliado aos benefícios latentes da justiça restaurativa para buscar soluções mais adequadas a cada caso concreto, seu manejo auxilia, ainda que de forma indireta, na redução de demandas no sistema judicial, nos casos em que ela possa atuar como substitutivo destes métodos tradicionais ${ }^{27}$.

Importante é salientar que a justiça restaurativa pertence a um movimento mais amplo de retomada, pelos envolvidos, das rédeas da solução a ser apresentada em determinado conflito, afastando, em certos casos, o poder do Estado soberano que, para se afirmar como detentor exclusivo de poder, limitou o exercício da autotutela para casos muito específicos (como a legítima defesa, o estado de necessidade, o desforço imediato para proteção da posse, dentre outros) e passou, ele próprio, a dar solução àquelas questões que transcendiam ao ordinário entendimento das partes, exercendo o monopólio da jurisdição ${ }^{28}$.

Esta ideia de que a "justiça" só ocorre quando há composição de conflito permeou, e ainda persiste, no seio da comunidade jurídica. Entidades de ensino jurídico, órgãos de classes, instituições públicas, ainda hoje se revestem da noção de que a boa prática jurídica não dispensa embates acalorados, retóricos e rebuscados, abarrotados de teses de alta complexidade e baixa resolutividade.

Os danos são latentes: aumento de demandas judiciais e desvalorização de meios extrajurídicos para solução dos litígios, situações estas agravadas pelos já apontados fenômenos da globalização e evolução tecnológica, que aumentaram as redes de relacionamentos e, consequentemente, os conflitos, levando à reflexão se a ideia da jurisdição como instrumento de "luta" deve continuar a influenciar e ser influenciada por esta cultura de litigiosidade.

Estes paradigmas, de que a culpa deve ser estabelecida ao violador da lei que pratique o crime, fazendo com que a justiça surja, apareça, sempre vença, aplique a dor adequada através de um procedimento legal, devem dar margem para que, em determinados casos, os

27 Muito embora, como vimos, a justiça restaurativa não seja mediação (e consequentemente não se enquadre, a rigor, como conciliação), é importante registrar que o CNJ, após três anos, volta a prever, como meta para a justiça estadual, a resolução de conflitos pelos métodos adequados de solução de disputas. Segundo o Justiça em Números 2018, o número de litígios resolvidos na justiça comum via acordo representou, apenas, $10,7 \%$ (dez inteiro e sete décimos por cento) do total de decisões definitivas proferidas pelos magistrados. (BRASIL. Conselho Nacional de Justiça. Priorizar conciliação voltará a ser meta da Justiça comum em 2019. Brasília. Notícia publicada em: 04 de dezembro de 2018, às 20h42min).

28 Tradicionalmente, afirma-se que o monopólio da jurisdição pelo Estado não se apresenta como mero substituto da autotutela. Isto porque o juiz não atua tão-somente em substituição às partes no litígio, mas sim para resolver a desordem criada em razão da lide, o que compromete a segurança, a certeza e até mesmo a ordem jurídica. (THEODORO JÚNIOR, Humberto. Jurisdição e competência. Belo Horizonte. Revista da Faculdade de Direito da UFMG. n. 38. 2000. p. 163-164). 
envolvidos na prática do fato lesivo sejam estimulados a descobrirem e decidirem as responsabilidades, a reparação do dano e o restabelecimento para todos, principalmente para a vítima, que deve ser minimamente cuidada, ouvida e restaurada, com a devida responsabilização, e admissão desta responsabilidade, pelo ofensor, com a devida participação destes, da comunidade e da sociedade neste processo $^{29}$.

Para tanto, Zehr, ao analisar sistemas de justiça, parte para resgatar tradições antigas da humanidade para lidar com a transgressão, baseada no senso comum. Longe de ser um sistema retributivo, entender a justiça divina não passa pela análise do "olho por olho", mas pela sua motivação, uma vez que a reação divina à transgressão é puramente normativa ${ }^{30}$.

Assim, por exemplo, a palavra "shalom" traduz uma busca por um direito que denota a perspectiva divina para a humanidade que se realiza através do cuidado de uns com os outros, buscando soluções que não façam somente o bem feito, mas que possam contemplar as necessidades concretas de cada indivíduo na comunidade, tendo por base o fato criminoso que levou todos àquela situação, mas ampliando o contexto para se voltar a cada ação individual ${ }^{31}$. Este é o caminho e o grande desafio da justiça restaurativa.

\section{A justiça restaurativa como instrumento para transformação de conflitos.}

Mais do que resolver a qualquer custo, a justiça restaurativa se apresenta como uma forma de entender que os conflitos são inevitáveis na vida humana e que a pura resolução de conflitos não produz a adequada e efetiva paz social. Faz parte de um movimento que, ao invés de sufocar o conflito, busca entender as raízes do mesmo, atacando não só os efeitos, mas as causas do mal que aflige os envolvidos.

Nas sociedades primitivas, ressalte-se que a meta da justiça era atingir consenso, com o objetivo de se buscar harmonia e reconciliação entre família e comunidade atingida por um fato lesivo, ao invés de se isolar e punir o causador da aflição. Buscar respaldos éticos e ideológicos para definir e aplicar a justiça nos mais variados casos é medida salutar para implementação de uma emancipação da sociedade ante o paternalismo estatal, proporcionando autonomia e solidariedade aos envolvidos. A justiça se torna, neste contexto,

29 ZEHR, Howard. Justiça restaurativa. Tradução Tônia Van Acker. São Paulo. Palas Athena. 2012. p. 36.

30 ZEHR, Howard. Trocando as lentes: um novo foco sobre o crime e a justiça. Tradução Tônia Van Acker. São Paulo. Palas Athena. 2008. p. 140.

31 SCURO NETO, Pedro; PEREIRA, Renato Tardelli. A justiça como fator de transformação de conflitos: princípios e implementação. São Paulo. Simpósio Internacional da iniciativa privada para a prevenção da criminalidade. NEST/Câmara de Comércio e Indústria Brasil/Alemanha. 2000. p. 4. 
um fator poderoso de agregação dos vários setores da comunidade ${ }^{32}$.

Some-se a isto a crise pela qual vem passando o modelo penal de justiça retributiva, eclodindo na deficiência de prevenção e repressão adequada aos fatos delituosos, seja porque os índices de criminalidade continuam aumentando ${ }^{33}$, seja ainda pela ausência da almejada (res)socialização do ofensor ${ }^{34}$.

Ainda, é chegado o momento de devolver aos envolvidos o poder de decidirem, se assim acharem conveniente, o melhor caminho para apontar soluções em eventos delituosos que provoquem danos, abandonando a visão de um Estado que pode e deve fazer tudo. Isto demanda várias mudanças, sobretudo da cultura e da mentalidade que permeiam a sociedade civil e o universo jurídico ${ }^{35}$.

No entanto, há de se ter o cuidado de não tornar a justiça restaurativa, e todos os métodos e técnicas que o envolvem, no que se costuma denominar de "mais do mesmo". A justiça restaurativa, e os demais métodos recentes de lidar com os conflitos na área penal, devem se debruçar sobre o conflito de forma diferente daquela apontada por Lederach em sua atuação na América Latina nos anos 80.

Como procedimento colaborativo voltado às transgressões, a justiça restaurativa deve dar um passo importante rumo a análise do conflito em todas as suas dimensões, buscando, mais do que "resolver" (e consequentemente abandonar a indesejada interpretação de que resolver um conflito é se livrar dele, aplicando uma solução imposta e autoritária), entender que o conflito é algo normal nos relacionamentos humanos e que se revela em um motor de mudanças $^{36}$, nem sempre ruins. Se o conflito é uma perturbação no fluxo natural dos

32 SCURO NETO, Pedro; PEREIRA, Renato Tardelli. A justiça como fator de transformação de conflitos: princípios e implementação. São Paulo. Simpósio Internacional da iniciativa privada para a prevenção da criminalidade. NEST/Câmara de Comércio e Indústria Brasil/Alemanha. 2000. p. 4.

33 Segundo o Levantamento Nacional de Informações Penitenciárias, entre 2004 e 2014, a taxa de aprisionamento no Brasil aumentou $67 \%$, seguindo na tendência contrária das maiores populações carcerárias do mundo. Disponível em <https://brasil.estadao.com.br/noticias/geral,taxa-de-aprisionamento-aumenta-67-em-10anos-no-brasil,10000028197>. Acesso em 12 de dezembro de 2018.

34 CARDOSO, Henrique Ribeiro; RESENDE NETO, Osvaldo. A importância de práticas da justiça restaurativa no combate ao tráfico de drogas. Curitiba. Revista de formas consensuais de solução de conflito. v. 2. n. 2. Jul/Dez. 2016. p. 187.

35 "No Brasil, há um ensino jurídico moldado pelo sistema da contradição (dialética) que forma guerreiros, profissionais combativos e treinados para a guerra, para a batalha, em torno de uma lide, em que duas forças opostas lutam entre si e só pode haver um vencedor. Todo caso tem dois lados polarizados. Quando um ganha, necessariamente, o outro tem que perder." (BACELLAR, Roberto Portugal; SANTOS, Mayta Lobo dos. Mudança de cultura para o desempenho de atividades em justiça restaurativa. In: BRASIL. Conselho Nacional de Justiça. Justiça restaurativa: horizontes a partir da Resolução CNJ 225. Coordenação: Fabrício Bittencourt da Cruz. Brasília. CNJ. 2016. p. 76).

36 LEDERACH, John Paul. Transformação de conflitos. Tradução de Tônia Van Acker. São Paulo. Palas Athena. 2012. p. 17. 
relacionamentos, nem sempre este fluxo está correto ou adequado a todos os envolvidos em determinado relacionamento humano.

A transformação suplanta a resolução, na medida em que enxerga o conflito como uma oportunidade de lidar com o contexto mais amplo, debruçando-se sobre o sistema de relacionamentos e padrões que levam aos fatos criminosos. Assim, a transformação, além de analisar as necessidades imediatas e urgentes, demanda uma visão mais profunda, proporcionando alívio imediato e soluções para que os padrões conflituosos não se repitam. Trata do episódio e do epicentro.

Nem todos os conflitos penais serão "transformados", ou se apresentarão em condições de transformação. Nem todos poderão ser. Alguns não encontram espaço para ter o que transformar. Entretanto, o modelo tradicional de lidar com os conflitos na seara penal não consegue lidar satisfatoriamente com os fatos delituosos, uma vez que se destina, tãosomente, a "resolver" os conflitos através da aplicação de uma decisão por um terceiro desinteressado na demanda penal.

Assim, como método que devolve aos envolvidos uma parcela de poder decisório, afastando-se do paternalismo estatal que nem sempre se demonstra necessário para a resolução dos conflitos, a justiça restaurativa deve lidar com os conflitos de forma plena, de modo a abandonar a visão de mera resolutividade das demandas penais, implementando uma cultura voltada, também, a por fim aos elementos nocivos ao relacionamento humano em que eclodiu o fato delituoso, bem como construir um caminho baseado em valores que se voltem, positivamente, aos envolvidos, acarretando em relação de ganhos a todos.

\section{CONCLUSÃO:}

O sistema penal encontra-se em franca revolução, na medida em que se conclui que os métodos tradicionais de lidar com as demandas, e seus procedimentos estruturais rígidos e padronizados, por focarem na prioritária determinação de culpas e sua consequente punição, apontam para métodos retributivos que se voltam a tão-somente punir o mal causado.

Diante deste quadro, diversos setores jurídicos e sociais vêm buscando, mesmo dentro da seara penal, mecanismos para lidar com os conflitos de forma satisfatória, afastando decisões impostas sem a participação e a construção dos envolvidos no fato socialmente relevante, tornando a resposta dada artificial e abstrata.

Para tanto, a justiça restaurativa retira o fato deste contexto abstrato e passa a encarar o 
crime como um dano e violação a pessoas e relacionamentos, voltando-se à reparação dos danos causados e à restauração das relações (inter)rompidas pelo conflito penal, com a participação de todos os envolvidos, que queiram e se sintam seguros, na construção da melhor resposta a ser dada naquele caso concreto ${ }^{37}$.

Ao abrir mão da visão retributivista no crime, em que o infrator é considerado uma pessoa ruim, produto de decisões erradas que tomou na vida, a justiça restaurativa também não enxerga nele um pobre coitado, pessoa problemática que não tem nenhuma culpa pelo ato que cometeu. Ao contrário, parte da ideia de que o infrator deve ter consciência de seus atos, admitir, ainda que parcialmente, o mal que causou, entendendo e assumindo suas consequências perante a vítima e demais envolvidos no episódio, partindo para uma decisão onde o ofensor seja estimulado a se comprometer e participar da construção das respostas.

No entanto, temos que ter o cuidado de não tornar a justiça restaurativa, e os demais métodos, técnicas e procedimentos que vêm surgindo como resposta a este tradicional modelo que não responde a todas as necessidades sociais, não se tornem "mais do mesmo", e se tornem meros modelos de (re)solução de conflitos.

Mais do que apresentar soluções a episódios de conflito, estes mecanismos devem buscar, cada vez mais, transformar tanto os episódios quanto os epicentros delituosos em energia apta à verdadeira reestruturação dos relacionamentos envolvidos nos fatos que levaram os envolvidos a elaborarem uma solução conjunta.

Portanto, estes novos procedimentos, dos quais se destaca a justiça restaurativa, devem se apresentar como verdadeiros métodos de revolução social, capazes de (re)integrar os personagens envolvidos no conflito, com o objetivo de que ponham fim às estruturas de relacionamento que não estejam funcionando, mantenham os laços que sejam benéficos a todas as partes e levem todos à construção de plataformas sociais, afetivas e relacionais de melhor qualidade. Resolver é importante; transformar é essencial.

37 Ou a "resposta correta" preconizada por Ronald Dworkin, qual seja, buscar, em cada caso concreto nos círculos restaurativos, que melhor interpretação pode ser dada, levando-se em conta o direito como integridade isto é, todo o processo de compreensão de uma sociedade sobre os fatos e princípios jurídicos, de modo a dar continuidade a essa história, corrigindo eventuais falhas, evitando assim novos conflitos e desnecessárias criações de "novos direitos". (PEDRON, Flávio Quinaud. Esclarecimentos sobre a tese da única "resposta correta”, de Ronald Dworkin. Brasília. Revista CEJ. Ano XIII. n. 45. abr./jun. 2009. p. 106). 


\section{REFERÊNCIAS:}

BACELLAR, Roberto Portugal; SANTOS, Mayta Lobo dos. Mudança de cultura para o desempenho de atividades em justiça restaurativa. In: BRASIL. Conselho Nacional de Justiça. Justiça restaurativa: horizontes a partir da Resolução CNJ 225. Coordenação: Fabrício Bittencourt da Cruz. Brasília. CNJ. 2016. p. 67-86.

BRASIL. Conselho Nacional de Justiça. Priorizar conciliação voltará a ser meta da Justiça comum em 2019. Brasília. Notícia publicada em: 04 de dezembro de 2018, às 20h42min. Disponível em <www.cnj.jus.br/noticias/cnj/8813-metas-e-encerramento>. Acesso em $11 / 12 / 2018$.

CARDOSO, Henrique Ribeiro; RESENDE NETO, Osvaldo. A importância de práticas da justiça restaurativa no combate ao tráfico de drogas. Curitiba. Revista de formas consensuais de solução de conflito. v. 2. n. 2. Jul/Dez. 2016. p. 186-206.

FACCHINI, Julia. O local nos estudos sobre peacebuilding: uma análise das obras de John Paul Lederach e Roger Mac Ginty. 26 f. Trabalho de Conclusão de Curso (Graduação em Relações Internacionais) - Universidade Federal de Uberlândia. Uberlândia. Disponível em <https://repositorio.ufu.br/handle/123456789/20734>. Acesso em 10 de dezembro de 2018.

GOMES, Ronaldo Martins. A democracia deliberativa de Jürgen Habermas. São Carlos. Anais do Seminário dos Estudantes da Pós-Graduação em Filosofia da UFSCar. VIII Edição. 2012. p. 476-497.

JUSTIÇA RESTAURATIVA. Profissão: Repórter. Rio de Janeiro. Rede Globo. 31 de outubro de 2018. Programa de TV. Disponível em < https://globoplay.globo.com/v/7129592>.

KELSEN, Hans. Teoria geral do direito e do estado. Tradução de Luís Carlos Borges. $3^{\mathrm{a}}$ ed. São Paulo. Martins Fontes. 1998.

LEDERACH, John Paul. Transformação de conflitos. Tradução de Tônia Van Acker. São Paulo. Palas Athena. 2012.

PEDRON, Flávio Quinaud. Esclarecimentos sobre a tese da única "resposta correta", de Ronald Dworkin. Brasília. Revista CEJ. Ano XIII. n. 45. abr./jun. 2009. p. 102-109.

RANQUETAT JÚNIOR, César A. Laicidade, laicismo e secularização: definindo e 
esclarecendo conceitos. Santa Maria. Revista Sociais \& Humanas CCSH/UFSM. V. 21. n. 1. 2008. p. 67-75.

SALMASO, Marcelo Nalesso. Uma mudança de paradigma e o ideal voltado à construção de uma cultura de paz. In: BRASIL. Conselho Nacional de Justiça. Justiça restaurativa: horizontes a partir da Resolução CNJ 225. Coordenação: Fabrício Bittencourt da Cruz. Brasília. CNJ. 2016. p. 15-64.

SILVA, Haroldo Luiz Rigo da. Justiça restaurativa - instrumento de efetivação do princípio constitucional da felicidade: um estudo sobre a prática em Sergipe. Dissertação (mestrado em Direito). São Cristóvão. UFS. 2017.

SUXBERGER, Antônio Henrique Graciano. Críticas ao consenso universal impositivo. p. 8390. In: $70^{\circ}$ aniversario de la declaración universal de derechos humanos: La protección internacional de los derechos humanos en cuestión. Valencia. Tirant lo Blanch. 2018.

THEODORO JÚNIOR, Humberto. Jurisdição e competência. Belo Horizonte. Revista da Faculdade de Direito da UFMG. n. 38. 2000. p. 145-182. Disponível em <https://www.direito.ufmg.br/revista/index.php/revista/article/viewFile/1167/1100>. Acesso em 11 de dezembro de 2018.

ZEHR, Howard. Justiça restaurativa. Tradução Tônia Van Acker. São Paulo. Palas Athena. 2012.

Trocando as lentes: um novo foco sobre o crime e a justiça. Tradução Tônia Van Acker. São Paulo. Palas Athena. 2008. 